\title{
The Philosophy of Sport as Artistic Expression
}

\author{
Danny Shorkend
}

Correspondence: Danny Shorkend.

\author{
Received: February 28, 2018 Accepted: March 15, 2018 Online Published: April 23, 2018 \\ doi:10.11114/ijecs.v1i1.3227 \\ URL: https://doi.org/10.11114/ijecs.v1i1.3227
}

\begin{abstract}
While there is no "expressive theory of sport", there is certainly, according to Hyland (1984, 1990), Osterhoudt (1973), Kerr (1997) and Weis (1969) a pivotal role played by emotions and feelings in sport which amount to a type of expressive theory and in that sense it parallels expressive theories in art. In this article I will first isolate three moments that capture sports performance and parallel art. Then, I will describe sport as an expression of emotional release, which is often how one understands art. Based on such overlaps, I will argue for two philosophical observations that devolve from such a comparison, namely ineffability and the unity of mind-body (in sport). Finally, I will apply a reading of Kant to sport, in order to substantiate the idea that sport, like art draws from a philosophical heritage.

Imagine three isolated "steps" in sport: the focus before performance; the performance itself and the fan's response as they articulate the emotional basis of sport which is familiar, albeit perhaps subconscious. After a brief analysis of these imagined images, I give a simplified historical outline of sport which describes the feeling-basis of play that forms the foundation for modern sport. I then examine what I have termed the "(surplus) expressive-energy theory of sport" which I have gleaned from the above writers, a theory that argues that sport is the expression of inner emotional states. Such states are in need of expiation of both the practitioner as well as the expression of certain basic emotions on the part of the audience. A narrower version of this theory is that sport is the release of aggressiveness, which coheres with its instinctual origins and the "surplus theory". A critique of sport as expression (of surplus energy, aggression...) follows with a view to highlight some shortcomings in the ideas presented and thus the need for further theories to account for the multi-faceted nature of sport, a similar requirement that is needed for art given the shortcomings of expressive theories as applied to the arts.
\end{abstract}

\section{Imagined Images}

Corresponding to the "images" in the phases and game of art, we find a similar tripartite system of emotions that is reflected in sport. First, there is the inner emotional state, the artists'/sportsperson's drive and will is highlighted as s/he mentally prepares her/himself for the task at hand (which needs to be supplemented with hours of physical training). One notes the necessary emotional involvement in the sports/art-act itself. To perform an action at optimum level the artist/sportsperson needs to emotionally immerse himself in it and be totally involved. We find that in many cases the sportsperson will yell and summon all his or her feeling while executing a particular manoeuvre. Although such points may be obvious, it a necessary link towards a conception of sport as fundamentally expressive. Lastly, we focus on aspects of the emotions and expressivity in sport/art as they relate to the viewer or fan. In these images, one can visualize a sense of the mass euphoria created by the sporting event or the cultural dialogue that follows an art event or exhibition. In addition, the individual or personal meaning that sport holds and the appreciation of good or bad play as the case may be, resulting in an expressive show of the emotions. Obviously, I am isolating very particular instances in order to make general points about art/sport itself. However, one could equally focus on one sport or art-form with its particular history (a knowledge-base or capital that players and fans alike may be privy to), its specific artistry and tempo - all of which create unique flavours of emotions at pertinent junctures within the time allotted within the confines of the said sport or art-form.. Thus, my argument is broad and general even as the images are associated with particular games.

\section{Genesis of Sport: a Broad Approach}

As my argument is broad and general in terms of isolating the expressiveness in sport and thus an expressive theory of sport, it is useful to consider how sport was said to have taken shape in terms of "expression", without recourse to a detailed history of sport, which is not the focus of this article.

Early man, according to Noakes ${ }^{1}$ (2010) and Olivova et al (1984) expressed their thoughts in song, poetry, story-telling,

\footnotetext{
${ }^{1}$ I conducted an interview with Tim Noakes (University of Cape Town) on the $20^{\text {th }}$ August 2010 and he shed light on the
} 
painting pictures, playing games (sport) and by evolving all sorts of customs and rituals. One of the particularly significant forms of expression was that of physical movement. A special body language was created, which was not only capable of expressing and communicating ideas but of passing them on from one generation to another. This particular function of physical activity, as distinct from utilitarian movement, was developed during man's free time - at festivals (Olivova 1984:76).

The result of such evolution meant that human beings no longer only needed to be concerned with food gathering, but learnt to store, thus providing periods of rest for eating, sex, making images and movement - indulgency of which submerged emotions of fear and aggression.

During the rest periods, communities would engage in various ceremonies or festivals. The power of these events contained an overlap of dance/sport/play/art which was brought to the fore in the organized bodily movement. There was a communal dance of an ecstatic kind, the catharsis of trance, elementary movements of the human body, gestures made in children's spontaneous games, and in useful daily tasks, mixed together. They ${ }^{2}$ would mimic movements of plants and animals, while including also the other senses like sounds (early form of music), as the leaping flames, intoxicating scents, beverages and drugs influenced the appearances of spirit - ancestors, defeated enemies in symbolic form. In all, it is believed that these ceremonies/festivals helped express human emotions as stories were told of the origins of world and man, the miracle of birth and mystery of death, of the community and its leading figures. The result was a complete physical and mental exhaustion which it is thought brought relief and relaxation to all - human happiness and creativity as human instincts had free play for a certain period of time, limited to the degree that there was social control. This freedom of expression was the "presenting in embryo the many activities that were later, after specific development, to separate disciplines, ranging from dance itself, to drama, painting...(and sport)" (Olivova 1984:14, brackets my inclusion).

The point of the above serves to articulate that human evolution leads to a certain athletic prowess (that is, "a special body language") and demonstrates that such athleticism was a basic or essential mode of human expression. If this thesis is correct than an expressive theory of sport, namely that sport allows for the expression of surplus energy or specific emotional states, may in fact be plausible, a thesis which is convincing to some degree when applied to that of art.

\section{Sport as the Expression (of [Surplus] Energy)}

To reiterate: The three images above divide the sporting experience in three segments forming a parallel to the three-tier system as applied to art. First, we have the image of focus, mental concentration, in short, an expression of inner calm and control. We may term such an image "the expression of the inner drive or intentions of the sportsperson" ("act 1"). Then we have the ubiquitous image of the excellent sports moment, capturing the performance or expression of the sportsperson in full flight as he or she brings all his or her resolve into the execution of a particular, perhaps complicated, movement or set of movements. He or she can be said to express him or herself through the medium that is his or her sporting code ("act 2"). The third image is the reaction of the fan/s reflecting a multitude of emotions and expressing pleasure or displeasure, as the case may be, in a particular play or even towards the sportsperson, coach, manager or team in general ("act 3"). All three cases show an expressive dimension that reflects a process (training, mental state of the sportsperson perhaps mediated by psychologists) and then expression in the actual event, the latter being a logical consequence of the former, a type of sequence that one can liken to Collingwood's "process-and-then-externalization theory". The appreciation or anger expressed by the supporter reflects a Tolstoyan-like sense of either kinship with the sportsperson/artist or indignation, wherein universal brotherhood is not expressed. ${ }^{3}$ This latter "act" of expression is paralleled by the athlete's joy or anger or the like at his or her performance, his or her response to the expressive action, if you like.

Focusing on the first "act" of expression - inner resolve/intention - we may follow Weis (1969) who argues that sport consists of the achievement of excellence and perfection ${ }^{4}$ and gives us a measure for what we do. It reveals to us the

fact that human evolution so predisposed man to engage in sporting-like activities, in fact it enabled such a progression into modern sporting codes.

2 This thesis is not a detailed anthropological account of early man. "They" refers quite generally to early man from Paleolithic man and their art/games/sport or hunt (30000-9000 BCE) to Neolithic man and their art/games/sport or hunt (8000 - 3000 BCE) up until the more settled and complex Ancient World (the premodern).

${ }^{3}$ Sport (like art) can create a great sense of national unity, but when a player cheats (disregards the rules, takes performance enhancing drugs, match-fixing...) or a referee blunders, this sense of bonding among people is often compromised.

${ }^{4}$ c.f. Perfectionism and mood states among recreational and elite athletes, Stirling, A \& Kerr, G (University of Toronto), 
magnitude of what can be done if energy is channelled and of what we can be at the limit of bodily capacity. The successful sportsperson intuits this and wishes to push the yardstick of human potential and make actual a new level of sporting excellence. It is only with a fine-tuned inner quiet, specifically before the expression in the actual sports event ("act 2") that leads to achievement in that performance. Noakes (2010) speaks here of the need to shut out the cortex, the analytical, conscious mind and focus, as in a meditative state on the task at hand, where analysing happens only on the subconscious level. In fact, at the higher levels of sport, a sports scientist may be required to teach sportspersons various techniques to enter that meditative state in order to be, as it were, "in the zone". The energy reserved for sport, the surplus needed, can then be utilized most favourably when the sportsperson overcomes fear and is ready, poised like a cheetah before the kill, for the task at hand. When this is done, the sportsperson expresses himself or herself most fully.

The second "act" of expression or channelling of surplus energy is the performance. If the first "act" is at its optimum, a good performance follows. Maslow (1954) speaks of such "peak experiences" which is a performance of a particular intensity, meaning and achievement. It is characterized by a certain focus, effortlessness, smoothness as if time slows and the performer exudes confidence. It is the addition of energy over and above one's usual amount or surplus. Pele (born 1941), the football player, describes such energy in the following way: “...it was a type of euphoria; I felt I could run all day without tiring, that I could dribble through any team or all of them, that I could almost pass through them physically. I felt I could not be hurt. It was a strange feeling and one I had not felt before" (in Hyland 1990:79).

This "surplus energy" is said to be expressed without thinking, as an unconscious activity where there is the non-interference of thoughts. Suzuki (1975:82) in Zen and the art of archery, describes it as a "letting go of yourself, leaving yourself...". When the sportsperson arrives at this state, his or her performance is greatly enhanced and he or she can become a hero, an international icon, one even more popular and sought after than the contemporary artist of notable fame. The romantic ideal of the artist appears in contemporary society to be reserved for the sportsperson who, aside from his sublime proficiency in his sport, is held to be a paragon of virtue, a representative of the indomitable human spirit.

This "extra" energy involved in sport and accounting for the high praise of the victorious sportsperson may have a philosophical rational as found in the writings of Dalcroz, Laban and Bode in Osterhoudt (1973). Each argue that movement is a medium of expression of soul/spirit/self, a harmonization of mind and body, "and communication of the self with others and larger metaphysical entities" (Osterhoudt 1973:6). That movement thereby frees expressive impulses bringing an unobstructed relationship with the Divine and a unity of mind, life and spirit, of science and art. Dalcroze (in Osterhoudt 1973) makes the point that movement harmonizes body and spirit and creates individuality which is the basis of the arts. Sport, he continues, is an idealized form of musical rhythm through which the whole of man's spatio-temporal familiarity is established. Laban (in Osterhoudt 1973:54) argues that movement is a kind of rhythmic relating and balancing of inner effects to environmental (external) forces (obstacles, challenges) and as such is a "medium of expression by which man's highest and most fundamental inspirations are cultivated and fulfilled" (in Osterhoudt 1973:6). Movement thus expresses inner life, an idea or flow - in summary: the content of the inner life in tangible form. Finally Bode (in Ostehoudt 1973) also sees movement as individual, instinctive rhythm and as freeing the individual towards fuller expression. In the case of all three theorists one may conclude that there is a greater ontological place enjoyed by movement. Movement is here understood and defined as the expression of energy and in its more successful form, as the expression of surplus energy. As such, it is through various movements that one can articulate an expressivity whose energy is at once disciplined and free. It is through these polarities, I believe that we find our fascination with sport as a constructive and meaningful form of human expression.

Furthermore, this notion of "surplus energy" enables a person to express an awareness of a subtler dimension of the self in relation to other selves. Fraleigh (in Osterhoudt 1973) argues that sport as expressive of "surplus energy" enables a sense of self-identity, making one aware of one's individuality and of being a member of humanity (hence the timeless significance of records). In Ancient Greece this was articulated as the idea of arête - manly excellence epitomized by the gods who were perfect men. The modern Olympic vernacular is faster (citius), higher (altius) and stronger (fortuis). In both cases the energy involved in sport are types of expression or a language which is full of symbols to dominate the world (that is, to create order, measure rhythm ${ }^{6}$ ).

\section{7 in Online Journal of Sport Psychology.}

${ }^{5}$ Many sportspersons will attest to the fact that their best play occurred when they almost lost control and cannot even remember what it is they did. Reviewing the play on video post-mortem, a common response is: "...that was not me".

${ }^{6}$ There is a curious link between the natural instinctual dimension of sport, for example the regalia of the sportsperson individually or in team sports resembles the recognition by one animal of another species, a distinguishing device that propels them to act in a certain manner - and the cultural, that is, instead of sport being instinctual, it is of cultural import and in this case, the special clothing and equipment are an assertion over and above the instinctual. 
One can substantiate the above (that sport is expression, a peculiar language) by acknowledging that "...there is no society known to man which does not have games of the sort in which individuals set up purely artificial obstacles and get satisfaction from overcoming them" (Weis 1969:8). Given this universality of sporting expression, it is not surprising that the notion of the athlete is that he or she represents all. It is as if the more we are driven to be and do our best, the better we epitomize all or represent the rest. Hence, we get the idealized portrait of self as expressed in the muscular body - in most cases - that typify the sportsperson. Weis (1969:22) inquires as to why young men wish to live up to this ideal and utilize their energies in sport as it requires discipline, possible failure and humiliation. He answers by saying that sport affords "opportunities to master the very way their energies are expressed". This expression of energy in such a context sharpens judgment and there are the benefits of strenuous work gained from discipline, and being pushed to the limit. He continues: "...they must, it seems, live through tensions and crisis before they can be at peace with themselves" (Weis 1969:22). This expression is also a surplus of joy, not simply energy to burn, one that builds character through overcoming obstacles, with the promise of elation in victory. The universality of sport and individuality converge producing heightened emotions.

I have been describing "act 1" and "act 2", which requires that they express themselves by accepting their bodies and thus training, by identifying with their equipment, by defining what they are by what they do. And in achieving that, I have argued, the sportsperson represents others. They can thus become heroes if they unite sufficiently with the game (an expression of love, exuberant energy) and equipment through their bodies to realize the mind's intentions. The result even if unconsciously - that the athlete aspires to, namely beauty, grace, co-ordination, responsiveness, alertness, efficiency, devotion and accomplishments, harmony, rhythm and flexibility. These are the attributes that set the athlete apart from others (as an individual but carries out a role larger than himself or herself as was often the case concerning the modernist artist).

Perhaps it is also necessary to add that I have been focusing on elite sportspersons and their plying of their craft to express that ill-defined energy within. There is, of course, also those people who do sport far less seriously, for whom sport is merely the after-effect of relaxation after conquest (Vanderzwaag 1972) or as Schiller describes it, as an "aimless expenditure of exuberant energy" (in Vanderzwaag 1972:109). Or sport may be a means of revitalizing after and for work. But even so, I contend that the elite athlete defines the way the recreational sportsperson approaches sport, whether simply for relaxation, to support a team or an individual. It is as if our fun and games also carry a kind of seriousness, a make-believe that we too sacrifice for the game in our efforts to compete and improve, at whatever level.

In the third "act" of expression the reader is referred to the images of the recipient/audience and the elation or depression of the athlete. The former, in particular, is clearly where we may see the role of sport, that is, as a source of inspiration not just because one is a spectator, but it's near universal quality of participation as mentioned hitherto. Sport for the audience is a space away from the pressures of life and allows those so inclined to express - even yell - an opinion or disagreement with the authorities, either the coach or officials. Goldstein (in Novak 1979:221) contends that most sports viewers are not merely spectators, but rather participants as are the true believers of the religious rituals to which Novak likens the sporting event. It is surely no coincidence that "fan" so closely resembles the word "fanatic". Likening the sports event to an expressive work of art, we may say that sports events provide a real-life drama containing the thrill of victory and the agony of defeat. As Goldstein (in Novak 1979:321) contends: “...only a hard fought battle produces the affect, the intensity of triumph and only the fully committed competitor suffers and agonizes."

Moreover, Crawford (2004) argues that the audience is part of the text itself - internet sites, fanzines and radio discussions which are then consumed by others and contribute to the text of the "live" game opens up expressive possibilities of the viewer, a kind of participation, if you will. In late capitalist society's consumer culture as evidence in sport is so heavily packaged, promoted, presented and played as commercial products (Crawford 2004). As such, the sporting event can become festival-like and combine a multitude of expressive possibilities. Whether this is just economic or that the sporting event has an almost religious significance as a form of worship (Begg 2010 ${ }^{7}$ ) given the festival-like atmosphere at the game, is not clear. The fan is said to be safe within the "festival", as he expresses various emotions. Psychologically, one can argue as Wann does (in Crawford 2004) that his behaviour acts as a buffer against depression and alienation. Furthermore, he contends it allows for a greater self-esteem and group esteem. Being knowledgeable about sports means a certain cultural capital that allows access to certain social groupings. Sport is said to be a useful discussion point which cross cuts class boundaries. This latter point is related more to the application to sport of the institutional theory, but I mention it here to make the point that sport provides for healthy expression as participant and as part of an audience. Therefore, getting rid of excess energy through sport is here perceived as healthy and meaningful.

\footnotetext{
${ }^{7}$ I interviewed Rashied Begg (University of Stellenbosch, $13^{\text {th }}$ September 2010), a sociologist, who also specializes in the sociology of sport, in particular its relationship to the media. He alerted me to the idea that within sporting events are embedded religious undercurrents, that the spectacle is a form of veneration not dissimilar to a ritual.
} 
Thus one may make the case that, indeed, playing sport or viewing sport is a form of expression, one which quells anger or expresses it, makes one feel better through exercise or tempers one's spirit when the team that one supports wins.

A narrower version of sport as the expression of energy or in particular, surplus energy, hitherto outlined, is that sport is the manifestation of aggression. Weis (1969) asks whether sport expresses an accidentally acquired cultural habit or admiration for successful violence within confined rules. In other words, sport is a way of being aggressive without actually subjugating and destroying.

However, the aggressive impulse need not monopolize the feelings expressed and I concur with Weis who thus says: “...sport is a constructive activity in which aggression plays a role together with dedication, cooperation, restraint, self-denial, and a respect for the rights and dignity of others" (Weis 1969:185). Sport expresses depth precisely because in spite of its obvious aggressiveness, the human spirit simultaneously reveals sensitivity, graciousness and humility. Perhaps that is why our culture emphasizes "sportsmanship".

Weis (1969) observes furthermore that in our culture where physical strength and agility are less necessary for daily life than before we elevate to hero status people whose activity exhibits just those increasingly anachronistic values. He says we do this as sporting prowess (feats of brute strength and aggression) reminds us of the way things were; it is a nostalgia for the past. Secondly, and in relation to the first point, sport engenders qualities that we are in danger of losing and want to preserve; thus it serves as a model of the way we want to be. Thirdly, spiritual values are involved, for example self-discipline, team-work, concentration and lastly sport, even as a mode of aggressive behaviour is a form of higher culture, a "soft" form of war such that sportspersons are seen as better than soldiers as agents of destruction (Hyland 1990).

This "aggressive"/expressive tendency means that the athletic competition/contest offers one of the few places where people can freely express their emotions without fear of censure, though within the confines of rules. Aggression in sport may be seen as the "opening" through which other emotions emerge. In other words, when sport is played aggressively, one is more likely to experience the range of emotions. Insofar as this is the case, sport can also express exhilaration, sadness, loneliness and so on. Its lessons are exhibited from and for life itself (that is, the metaphor of life as a game). Therefore, it requires courage in overcoming obstacles, perseverance or the folding under pressure. In summary, sport and sporting activity can express something of our passion or personal standpoint in the way we play ${ }^{8}$ inspired by a certain tenacity or aggressiveness.

In view of the above, Hyland (1990) argues that to play (sport) requires being more aware of things - a certain openness which he here calls a phenomenology of aesthetic and sensuous play. Other than "openness", a certain responsiveness is required, which is here defined as thematizing, which is to work with the finite and bring out the best, via freedom. It is pertinent to note that Hyland (1990) argues that this "openness" and "responsiveness" parallels artistic creativity. Both are said to also include a modicum of improvisation. All three attributes are said to be fun. I think "fun" should not be taken lightly. At the highest levels of sporting (and artistic) achievement, pleasure or fun is a necessary motivational and performance-enhancing aspect of what it means to play the game. To take pleasure in what one does is certainly an important factor in expressing oneself and continuing or persevering in one's chosen medium/sport. Aggression may be a significant aspect of "openness", "responsiveness", "improvisation" and "fun".

\section{Two Surface Observations}

Having outlined various aspects of the expressive theory in art and how that may apply to sport, this section proposes two observations, and a certain confluence. In the process, one may reclaim the expressive theory as explanatory of both art and sport in some measure without grand claims that the individual and the body of work expresses "truth" as such.

\section{Observation 1: An expression above language and towards the ineffable}

Our findings above concern the fact that physical activity and picture-making is crucial to our evolution; they need their primitive roots. Such activity, it was noted, in both art-making and sport are also trans-rational and thus beyond the analytical mind. Furthermore, both are perfected through training, and require the special inner drive and intuition. The upshot of all this is that the artist and sportsperson allow us to extend the range of our expressive powers beyond that which we find within our own resources. For example, one may say that a Rothko or Bannister's running helps me to express a feeling which defies description. One may attribute to such performances a kind of sombreness, serenity, even

8 This counters Best's (1979) argument that sport, unlike art cannot be said to comment on or reflect life issues. I suggest that indeed they do: the way a sportsperson chooses to express himself not only has national and political ramifications, but the actual way he/she performs speak of an individual philosophical statement (such as: freedom in movement, group cohesion, peaceful co-existence and so on). 
the mystical. It is, perhaps as Kandinsky (in Jansen 1967:115) says: “...painting (sport)...needs its materiality for that very dematerialization that shows the road from the external to the internal" (brackets my inclusion).

Via the "external" of say, a Newman painting, the onlooker may become aware of his own body. It is therefore no surprise that Newman asked his viewers to see his paintings close-up wherein a sense of the aliveness of the onlooker was conjured, a sense of place and awareness as opposed to separation. The visual experience may be said to be permeated with emotion. I would claim that to follow sports events on television does a similar thing to the onlooker. The "external" close-up of the action vitalizes the viewer. In this close-up, we may experience a kind of non-verbal identification with the "external" that borders on the ineffable.

As for the practitioner of art and sport, one may surmise that in striving he or she can experience wholeness. By expressing themselves, they "press" themselves out. This "pressing themselves out" is like love and friendship which is both predicated on a lack and a giving of self. Similar perhaps to a Tolstoian desire to communicate and share, the practitioner is in a position to express "... a gift of the abundance of what we all are" (Hyland 1990:141). This is expressed in the non-verbal language of art and sport. The language of the sporting event or artwork may have the veneer of linear time and logic, but in reality, given their primitive origins, they are both expressions of an intense unnamed emotional need that defies verbal articulation. Metaphorically, we can say it is like that ballet move or that sound without being able to pinpoint exactly what that movement or that sound expresses (or is).

In order to perform at a high level, one has to become one with the game or one with the act of painting or be in that ballet movement or in that sound, just flowing with it with full concentration. To the extent that one can do that, the sportsperson may say "the game played me" or the painting told me what $i t$ wanted. This attitude transcends competitiveness. Bannister, the famous sub four minute miler expressed a great sense of thankfulness at fulfilling his aims, rather than a sense of vanquishing his opponent. In sport as in art, one is ultimately against oneself. This means that both sport and art require introspection and incessant refinement to find and express that spark within. That "spark" is not easy to define - one may be able to express it in the repetition of the same great play and by forging a style. One has thus said it non-verbally and beyond conventional language.

Keenen (in Osterhoudt 1973), argues that sport is like theatre, in that it consists in performances within a special and contrived world, as "an idealization of the everyday". Like dramatic tragedy it has its "acts", for example, half time; "players" refer both to sportsmen and women and actors and actresses; there is clapping for a good performance and a quest for the great struggle. Camus (1913-1960) in Osterhoudt (1973:306) says: “...even today, the stadium crammed full of spectators for a Sunday match and the theatre which I loved with unequal intensity are the only places in the world where I felt innocent". I believe that this "innocence" felt by Camus can be located in the primordial child-like quality to find meaning in games, the spirit demonstrated by the "players" and the inexpressible somehow represented to the senses as an aesthetic experience.

Womack (2003) concurs that the arts and sport are mediums of expression without recourse to words when she says, "sport communicates through the language of symbols and, like art, it dramatizes complex ideas that cannot readily be expressed in words" (Womack 2003:27). In this light, one can make the brief argument that Yves Klein (1930-1965), an artist and expert judoka, sought an overlap of his love for art and understanding of the art and science of judo. He sought to express that which is above words in his performances ${ }^{9}$ and paintings. Klein's blue monochromes were his language that creates a sense of weightlessness, the essence of a correct judo technique and spatial determinacy. The viewer may feel drawn into the depth of blue that appeared to transmute the material substance of the painting support into an incorporeal quality, tranquil and serene (adapted from Weitmeier 1995:19). I cannot say it better than Yves Klein himself: "What is blue? Blue is the invisible becoming visible ... blue has no dimensions. It is beyond the dimensions of which other colors partake" (in Weitmeier 1995:19). I believe it was this same ineffable search that he sought in art and through judo-movements, that the latter could also suggest a boundless sensibility, that which "has no dimensions".

While I have been describing how an art-like perception may apply to sport, paradoxically they both appear to "refer" to that which defies expression. Nevertheless, it is hoped that both can be experienced aesthetically and that they do bear some similarities in these respects. Of course that acknowledgement cannot be mandated; it is but an argument. In this respect, the idea as to what constitutes the (a) aesthetic is a healthy debate.

\section{Observation 2: The integration of mind-and-body}

I have been arguing that emotions and the expression thereof play a pivotal role in both art and sport. Now if emotions can be construed as the link between the bodily and mental, then an expressive theory of both art and sport could account for

\footnotetext{
9 For example his performance piece "Leap into the void" (1960) demonstrates the freedom of art and judo simultaneously.
} 
a meaningful interweaving of mind-and-body through such endeavours. The benefit of such an "interweaving" is that art and sport galvanize people in meaningful ways. Weiss (1969:39) puts it like this: “...because art and sport involve a controlled expression of emotions, making it possible for minds and bodies to be harmonized clearly and intensely, they offer excellent agencies for unifying men". Shusterman's somaesthetics, rationalised with recourse to significant philosophers points to the unity of mind-and-body and the interrelation between sensory experience, feelings and cognition, often using the phrase body-mind or mind-body.

The individual too may benefit from this mind-body relationship. Weiss (1969:54) once more says: “...only he who expresses his emotions through such a possessed and structured body can become well-unified and not be undone by what he feels". In this process, the artist and sportsperson is said to have a mind to quicken and guide his body and a body as a source for acts desirable and effective. It is a body used, not simply worked on by what is external to it. Weiss thus uses the analogy of not hand-in-glove to represent the nature of the mind and body and its apparent dualism, a perennial problem in philosophy. Rather the mind-body interaction is like fingers to a hand - the fingers or body presuppose a hand or mind. Through practice both tend towards a rule-governed, well-controlled action. It is in this action defined as "act 2" that we can grasp a sense of unity and integration of the self.

To unpack this further, we may say that there is a similar process and language at work in both art and sport. There is first a desire, then more clarified intentions, followed by "performance" which contribute to the realisation of a prospect and finally commitment to continue performing in a certain way. This requires focus. I tend towards a phenomenological position which describes the unity of mental and physical activity as a kind of "lived body" in opposition to dualism. According to the phenomenological position, expression itself is considered a unified whole and an "integration" mentioned above. Hyland (1990:102) puts it in these terms:

... an amalgam of man's incarnation reveals that man is an opaque and partially concealed being

subject without clear and precise points of demarcation for the various aspects of his being; he is a

unity of physical, background and psychological relationships necessarily interrelated and only

meaningfully investigated when analysed as a whole.

This "unity" means that I do not simply have a body, but, in some sense, I am my body, and in sharper terms: mind, senses and use of the body cannot be isolated and mechanically described, all act in unison which is an expression of the "I".

Furthermore, in the same way that the artist forms a style and his individuality vitalized by artistic feeling and training in his craft, so too is the sportsman inspired by feeling and training in his craft. The net result of this may be perceived as "...a reunification of spiritual and corporeal faculties, that can be achieved only by an assiduous training in movement in time and space, and a diligent cultivation of a muscular strength" (Osterhoudt 1973: 42). This point applies equally well to the arts because movement too is a basis for the arts. One needs to train our motor-tactile faculties, and expression is a succession of movements. Even where the art is more conceptual and abstract as in the case of music, there is an imaginative construction of movement as the music has a rhythm which could be applied to a dance routine, and its "playing" certainly requires a certain dexterity and the like. In recognizing the indissoluble link between the mind-and-body in sport and art, one can say both activities have the potential to express a unity of self. This "unity of self" exists because the aesthetic can be embodied, that is, expressed.

An extension of sport aesthetics by applying Guyer's "Kant and the philosophy of Architecture"

In this section I apply a reading of Guyer on Kant in which he argues that Kantian aesthetics and metaphysics may be read so as to argue that sport is concerned with the expression of aesthetic ideas. In this sense, sport is not just formal aesthetic "play', but grounded in extra-aesthetic meaning-making comparable to the arts. The argument is based on the fact that Kant shifted his attention away from the arts as simply about disinterested formal harmony that tends towards the "mere" practical and beautifying logic in architecture, but that the latter is concerned with the expression of ideas. The very fact that this may be applied to architecture - a practical art - may lead to the argument that other aesthetic and perhaps more practical domains like sport can be similarly described.

Kant did not write much about architecture in his aesthetic deliberations and has had little influence in the theory of architecture. Nevertheless, Guyer (2011) argues that given the indisputable influence of Kant's aesthetics on German Idealism in particular after the 1790 Critique of Judgement, it seems natural to look for the shift in philosophical thinking about architecture within Kant's aesthetics. This shift, explains Guyer (2012:15) is from a Vitruvian conception of architecture, where the main goals of architecture are utility and beauty, to a cognitivist or expressivist conception of architecture. The expressivist is here understood as, like other forms of art, as communicating abstract ideas, not just aiming for beauty and utility. This shift can be seen in Kant's thesis that all art involves the expression of "aesthetic ideas", that is the expression of rational ideas in a form that yields inexhaustible material for the play of the imagination. Guyer further maintains that given Kant's "loose specification" of just what sort of intellectual content aesthetic ideas have, 
means that it could express 1) its own function, 2) nature of its structure, 3) the physical forces that underlie the structure and 4) metaphysical ideas (adapted from Guyer 2011: 5-12). In this regard, form is merely a springboard to that which is not-form, that is, meaning-making.

The very fact that Guyer has applied Kant's aesthetics to the realm of architecture, usually considered an applied art and not art as such, perhaps invites an even more radical shift of Kant's thought to other domains. In light of the proposition that art and sport share an aesthetic dimension, applying Kant's thoughts on "aesthetic ideas" to that of sport, is not far fetched. Sport expresses, albeit covertly in many cases: functionality (1), structure (2), physics (3) and even "deep" content (4) which I shall unpack in what follows.

Sport's movement is functional (1) in the sense that it requires economical movement. In fact, the founder of judo, Jigora Kano describes the excellent judo technique as one where efficiency and economical movement will lead to a successful throw. In being functional, sport has a formal, structural cohesion (2) that is expressed in the very "logic" of a series of movements. What appeals to the observer and what needs to be at play in participating in most sports is a certain composure - both bodily and in terms of mental focus. Thirdly, the tensions, the gravity, the inertia, the energy expressed by a sports movement, exemplifies physics in the form of action (3). Many sports somehow encapsulate in visually pleasing ways the potential of the body (mind) at the precipice of physical (and mental) possibility. We admire and praise how the sportsman (artist) uses his/her craft to show us what can be achieved through his/her mastery of the sport (art) within the confines of the limitation - temporarily overcome - of our embodiment. Lastly, there is a metaphysical aspect (4) in that the first three more physical attributes are all given impetus by human will. Will itself, in a kind of Schopenhaurian and Nietzschian sense, might be a more fundamental or metaphysical property "behind" the veil of nature and natural movement, giving one an intuitive sense of action that defies the ordinary, which might be particularly evident in sport especially at the elite level. The expression of will-power, of surmounting difficulties by performing optimally in sports-acts (or through art) is simultaneously an expression of the spirit, hence we emotionally identify with the sportsmen and women (or artists for that matter) that express and ply their craft come what may.

To unravel further what the sportsperson and artist may express other than simply the effort in expression itself, I concur with Guyer's claim that Kant's influence on architecture may be responsible for the idea that not only that it (architecture...) should express ideas, but specifically what those ideas should be. For example, in the case of the post-Kantian leading philosophers, such as Schelling, Schopenhauer and Hegel, one detects this Kantian influence. In the case of Schelling, Guyer (2011) argues that architecture, in order to be art, need not be concerned with utility as such, but as the expression of something intellectual. By this he may mean, in his words that: "...the most primal sequence is numbers...that architecture, as the music of the plastic arts, thus necessarily follows arithmetical relationships" (in Guyer 2011:11). Architecture should express or symbolise arithmetical relationships; that should be the architects goal. Schopenhauer argued that, as Guyer (2011: 12) simplifies: “...that the work of architecture should express not their function, but rather the nature of their own construction and the physical forces involved in and affecting that construction". With Hegel, architecture should express metaphysical ideas about divinity and spirit (here equated with reason) itself, but that this project is undermined as "art, considered in its highest vocation, is and remains for us a thing of the past" (in Guyer 2011:13).

This account above serves to suggest that Kant influenced these philosophers in their move away from architecture as utility towards an expression of aesthetic ideas. Kant's attempt to explain what these ideas consist of, however, deconstruct in his own writing, as form and matter, that which suggests rich intellectual content, "cannot be reduced to any rule but instead triggers inexhaustible and pleasurable motion or free play in the mind of its audience" (in Guyer 2011:16). With this, the door is opened for an expansive theory and practice of art, and this applies to architecture as well. The implication for sport, if we are to maintain that it does express aesthetic ideas, is that an overarching discursive theory of sport is not forthcoming as its form - the evolution of existing games and the creation of new games - forever changes and grows exponentially. In this spirit, one might maintain that sport does express a kind of mathematical pattern according to Schelling; that sport does express the coming together of natural forces according to Schopenhauer and that the "death of art" posited by Hegel is itself a thing of the past, as art aesthetics does exist in spheres usually considered not aesthetic, such as sport. The shift from a Vitruvian conception of architecture to an expressive one may be read in postmodern terms as a shift from an aesthetic-technicist conception of sport to an aesthetic-expressive one in the Kantian sense.

If sport, drawing from artistic expressive theories, can be understood as expressive, then it is likely that we would be able to find "moments" in traditional aesthetics where there is a shift for considering "other" activities as aesthetically expressive. Thus the suggested confluence between art and sport opens an inter and trans disciplinary exploration which I believe will yield significant ways of understanding and in fact developing both disciplines in both theory and practice. 


\section{References}

Collingwood, R. (1936). The principles of art. New York: Oxford University Press.

Crawford, G. (2004). Consuming sport: fans, space and culture. London: Routledge.

Croce, B. (1956 [1912]). Aesthetics. New York: Noonday.

Crowther, P. (1984). Kant and Greenberg's varieties of aesthetic formalism. The Journal of Aesthetics and Art Criticism 42(4), 442-445. https://doi.org/10.2307/430218

Hyland, D. A. (1984). The question of play. Washington: University Press of America.

Hyland, D. A. (1990). Philosophy of sport. Maryland: University Press of America.

Janson, F. (1967). History of art. New York: Prentice Hall.

Jarvie, G. (2006). Sport, culture and society: an introduction. New York: Routledge.

Kerr, J. H. (1997). Motivation and emotion in sport: reversal theory. Brighton: Psychology.

Olivova, V. (1984). Sports and games in the ancient world. London: Orbis.

Osterhoudt, R. (ed). (1973). The philosophy of sport. New York: Charles Thomas. Shusterman, R. 1997. The end of aesthetic experience. The Journal of Aesthetics and Art Criticism, 55(1), 29-41.

Shusterman, R. (2008). Body consciousness: a philosophy of mindfulness and somaaesthetics. New York: Cambridge University Press. https://doi.org/10.1017/CBO9780511802829

Suzuki, D. (1975). Zen and the art of archery. London: Penguin.

Swift, S. (2006). Romanticism, literature and philosophy. London: Continuum.

Tolstoy, L. (1898). What is art? London: The Brotherhood.

Van der Zwaag, H. J. (1972). Toward a philosophy of sport. Fort Worth: University of Texas Press.

Weitemeier, H. (1995). Yves Klein. Berlin: Benedict Taschen.

Weiss, P. (1969). Sport: a philosophic inquiry. Illinois: South Illinois University Press.

Welsch, W. (2005). Sport - viewed aesthetically and even as art? From The Aesthetics of Everyday Life, Light, A \& Smith, J. M. (ed.). New York: Columbia University Press, 135-155.

Welsch, D., \& Eaves, M. (2005). Expressive theory and Blake's audience. PMCA, 96(2), 273-275.

Womack, M. (2003). Sport as symbol: images of the athlete in art. London: McFarlend \& Co.

\section{Copyrights}

Copyright for this article is retained by the author(s), with first publication rights granted to the journal.

This is an open-access article distributed under the terms and conditions of the Creative Commons Attribution license (http://creativecommons.org/licenses/by/4.0/). 